$\begin{gathered}\text { Науковий вісник НлТУ України } \\ \text { Scientific Bulletin of UNFU } \\ \text { https://nv.nltu.edu.ua }\end{gathered}$
$\begin{gathered}\text { https://doi.org/10.15421/40281003 } \\ \text { Article received 08.11.2018 p. }\end{gathered}$
Article accepted 29.11.2018 p.
ISSN 2519-2477 (online)

Д. М. Голяка ${ }^{1}$ Х. Като ${ }^{2}$ В. І. Йощенко , Я. Ігараші ${ }^{3}$, Ю. Онда², О. О. Аврамчук', М. А. Голяка', В. В. Гуменюк 1 , О. М. Леснік ${ }^{1}$

${ }^{1}$ Національний університет біоресурсів і природокористування Украӥни, м. Київ, Украйна ${ }^{2}$ Цукубський університет, м. Цукуба, Японія ${ }^{3}$ Фукусімський університет, м. Фукусіма, Японія

\title{
ІДЕНТИФІКАЦІЯ ТА ОЦІНЮВАННЯ ВИСОТ ДЕРЕВ СОСНИ ЗВИЧАЙНОЇ У НАСАДЖЕННЯХ ЧОРНОБИЛЬСЬКОЇ ЗОНИ ВІДЧУЖЕННЯ СТЕРЕОФОТОГРАММЕТРИЧНИМ СПОСОБОМ
}

\begin{abstract}
Розглянуто можливості використання аерофотозйомки за допомогою безпілотного літального апарату та подальшого оброблення отриманих зображень стереофотограмметричними підходами для ідентифікації дерев сосни звичайної та оцінки їх висоти у зімкнутих деревостанах способом порівняння даних, отриманих для кругової пробної площі внаслідок аерофотозйомки та в польових умовах лазерно-оптичними далекомірами, що використані як контрольні значення. Встановлено можливість ідентифікації верхівок стовбурів дерев сосни звичайної за допомогою алгоритмів пошуку максимумів растрів у програмних продуктах ГІС. Підтверджено неможливість детектування дерев нижніх елементів ярусу шляхом застосування радіусів пошуку максимумів малих розмірів $(0,5$ м), що спричиняє помилкову ідентифікацію значної кількості локальних максимумів (бокових гілок) як окремих дерев. Збільшення розмірів радіусу фільтрації виявлення максимальних значень растра цифрової моделі висоти крони досліджуваного деревостану до 1 м дало змогу 3 достатньою точністю оцінити висоту (стандартне відхилення 0,44 м) 27 дерев у верхній частині лісового пологу. Це свідчить про перспективність використання перелічених підходів для встановлення лісотаксаційних параметрів насаджень не лише з науковою метою, а й під час проведення лісовпорядкування і лісоінвентаризації, оскільки верхня висота деревостану має тісні функціональні зв'язки з іншими таксаційними ознаками.
\end{abstract}

Ключові слова: безпілотний літальний апарат; лісова таксація; дерево; аерозйомка; ГІС; растр; модель висоти крон (CHM).

Вступ. Збільшення обчислювальних можливостей інформаційних технологій, значне поліпшення цифрової зйомки оптичними камерами, підвищення точності геопросторового позиціювання та багато інших факторів уможливили використання безпілотних літальних апаратів (БПЛА) для картування локальних об'єктів, що мають невелику площу. Розвиток програмного забезпечення (ПЗ) в напрямку фотограмметрії дав змогу створювати різні форми представлення досліджуваних те-

риторій у 3D просторі та будувати цифрову модель рельєфу (DEM) чи (або) місцевості (DSM), а також ортофотоплани, спираючись на великі колекції цифрових фотозображень та їх метадані. Наразі на ринку існує велика кількість конкуруючих пакетів ПЗ за цим напрямком, найвідомішими з яких є Agisoft Photoscan, Drone Deploy, Pix 4D та ін. Професійні версії цих продуктів дають змогу вирішувати велику кількість завдань, що постають під час моніторингових досліджень де-

Інформація про авторів:

Голяка Дмитрій Миколайович, канд. с.-г. наук, ст. наук. співробітник, Український науково-дослідний інститут сільськогосподарської радіологіï. Email: holyaka_d_m@ukr.net; https://orcid.org/0000-0001-8025-8885

Като Хіроакі, д-р філософії, доцент, асоційований професор, Центр дослідження ізотопів та екологічної динаміки. Email: kato.hiroaki.ka@u.tsukuba.ac.jp

Йощенко Василь Іванович, канд. біол. наук, проектний професор, Інститут радіоактивності навколишнього середовища. Email: r705@ipc.fukushima-u.ac.jp

Ігараші Ясунорі, доктор філософії, постдок, проектний дослідник, Інститут радіоактивності навколишнього середовища. Етаі: $y$ igarashi@ipc.fukushima-u.ac.jp; https://orcid.org/0000-0003-1386-0977

Онда Юічі, д-р наук, професор (повний), адміністративний керівник, Центр досліджень ізотопів і динаміки середовища. Email: onda@geoenv.tsukuba.ac.jp

Аврамчук Олексій Олексійович, мол. наук. співробітник. Email: a_avram@ukr.net

Голяка Марина Андріївна, канд. с.-г. наук, мол. наук. співробітник. Email: maruna.nybip@gmail.com

Гуменюк Василь Володимирович, канд. с.-г. наук, ст. викладач. Email: vasyl.gumeniuk@gmail.com

Леснік Олександр Миколайович, канд. с.-г. наук, мол. наук. співробітник. Email: alexlesnik09@ukr.net

Цитування за ДСТУ: Голяка Д. М., Като Х., Йощенко В. І., та ін. Ідентифікація та оцінювання висот дерев сосни звичайної у насадженнях Чорнобильської зони відчуження стереофотограмметричним способом. Науковий вісник НЛтУ України. 2018, т. 28, № 10. C. 18-21.

Citation APA: Holiaka, D. M., Kato, H., Yoschenko, V. I., et al. (2018). Identification and estimation of heights of scots pine trees in forest stands in the Chernobyl exclusion zone using stereophotogrammetry method. Scientific Bulletin of UNFU, 28(10), 18-21. https://doi.org/10.15421/40281003 
рев'янистих фітоценозів, представлених як високоповнотними деревостанами, так і поодинокими чагарниковими угрупованнями рослинності.

На підставі фотографічних матеріалів, отриманих 3 БПЛА за допомогою цифрових стереофотограмметричних підходів, реалізовано алгоритми ідентифікації верхівок дерев (Mohan et al., 2017), встановлення їх висоти (Wallace et al., 2016), розділення крон дерев та оцінки їх площі (або діаметрів) проекцій (Panagiotidis et al., 2017), розпізнавання деревних видів за закономірностями форми поверхні крони (Brovkina et al., 2018) та інші (Puliti et al., 2017; Giannetti et al., 2018; Oteroa et al., 2018; Abdollahnejad et al., 2018). Аналіз наукових робіт за цією тематикою виявив певну неоднозначність у вихідних результатах, отриманих щойно переліченими методами (Goodbody et al., 2017), що спричинено високими показниками точності використовуваних алгоритмів для встановлення параметрів поодиноко ростучих дерев і кущів, а також паркових і старовікових деревостанів, та зазвичай незадовільними результатами для зімкнутих листяних деревостанів. Однак зазначена технологія може вдало застосовуватись для покращення лісоінвентиризаційних чи лісовпорядних робіт, або реалізації радіоекологічного моніторингу лісових екосистем в межах Чорнобильської зони відчуження, зокрема у важкодоступних місцях та в разі високих рівнів радіоактивного забруднення лісових ділянок. Значну перевагу зазначені підходи можуть мати для відбору репрезентативних ділянок лісу, як проміжної ланки за використання даних супутникового моніторингу, тому що ортофоплани і цифрові моделі просторових об'єктів, отримані цим способом, мають значно більшу роздільну здатність.

Мета дослідження - апробація стереофотограмметричного оброблення цифрових отриманих із БПЛА зображень для оцінки кількості дерев сосни звичайної та їх висот у Чорнобильській зоні відчуження.
Матеріал та методи дослідження. Дослідження проводили в лісовому фонді ДСП "Північна пуща" у Луб'янському лісництві на південній межі 20 виділу 314 кварталу (географічні координати GPS WGS 84: $\mathrm{N} 51,354^{\circ}$ E $29,990^{\circ}$ ), на круговій пробній площі радіусом 12,6 м, що представлена різновіковими молодими деревами сосни звичайної (до 30 років). Середня висота деревостану становила 12,6 м.

Аерофотозйомку виконано квадрокоптером компанії DJI, модель Pantom 4 Pro стандартної комплектації, на висоті 40 м від поверхні грунту. Стереофотограмметричну обробку здійснено за допомогою програмного продукту Agisoft Photoscan 1.4.4. Вихідні растри DSM i DEM оброблено зі застосуванням пакетів ПЗ QGIS 2.18.15 та ArcGIS 10.6. Встановлення розташування дерев та їх висот, на підставі аерозйомки, здійснено з використанням фільтру "Focal Statistics" групи інструментів "Spatial Analyst" П3 ArcGIS із радіусом пошуку максимальних значень $(R)$ 0,5, 0,75 та 1,0 м на вихідному pacтрі Canopy height model (CHM), який розраховано як різницю DSM i DEM. Розміщення і висоту дерев у польових умовах ручним способом оцінено лазерно-оптичним далекоміром TruPulse $360 B$ з використанням ПЗ MapSmart (Laser Technology, Inc.). Отримані польові дані використано як фактичні (контрольні) показники для оцінення якості ідентифікації дерев і встановлення їх висоти методом стереофотограмметричного оброблення фото з БПЛА.

Результати дослідження. На рис. 1 представлено, в межах круглої пробної площі, ортофоплан із фактичним розміщенням дерев і значеннями виміряних висот дерев ручним лазерно-оптичним далекоміром, а також частину СНМ растра з ймовірними "верхівками" зі застосуванням фільтрування максимальних значень різних радіусів, що надалі використовуватимуться для можливостей розпізнавання дерев сосни звичайної.
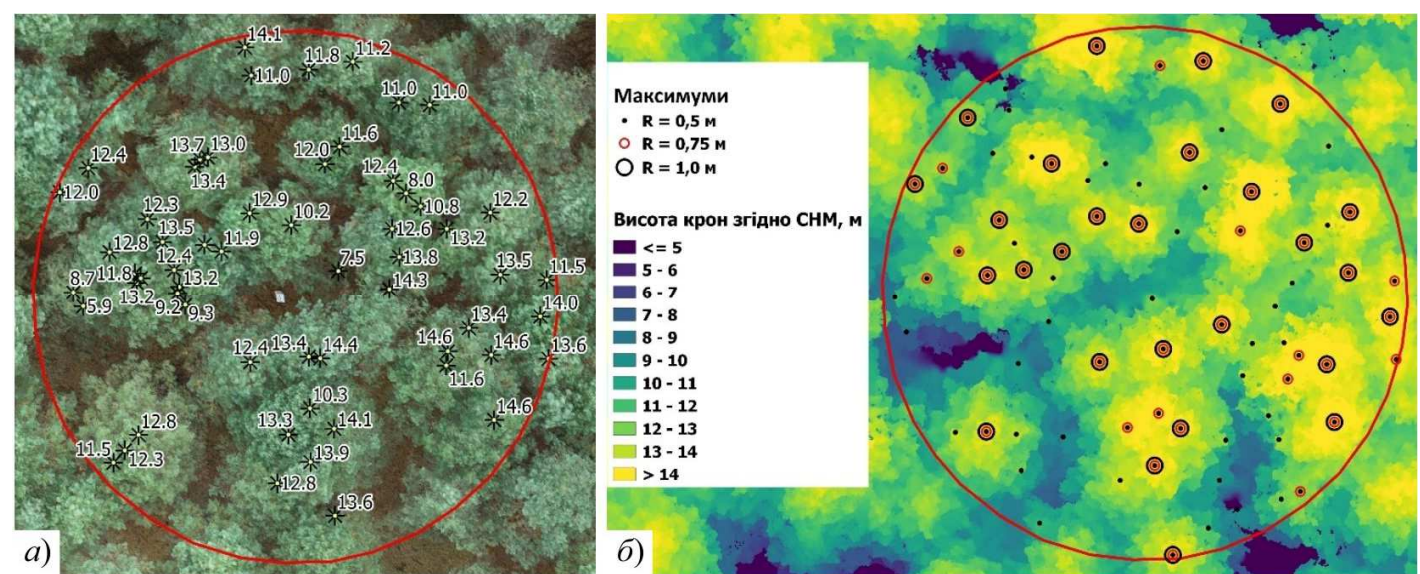

Рис. 1. Вихідні зображення аерозйомки: а) ортофотоплан із фактичним розміщенням дерев і їх значеннями висоти; б) СНМ із ідентифікованими максимумами

Аналіз зображень на рис. 1 вказує на цілком закономірне збільшення кількості максимумів при фільтрації СНМ растра радіусами менших розмірів. Так, при ідентифікації $R=0,5$ м з'являється велика кількість максимумів, що не відповідають реальним верхівкам стовбурів. Однак у верхньому діапазоні висот (12,5-15,4 м) практично всі реальні верхівки дерев були ідентифіковані (30 із 31 стовбурів дерев). Зі збільшенням радіуса фільтрації пікселів СНМ спостерігається зменшення кількості виявлених максимумів, хоча зростає їх частка відповідності фактичним стовбурам дерев на круговій пробній площі (таблиця).

Обговорення результатів дослідження. Реалізація підходів дистанційної оцінки кількості і висоти дерев для зімкнутих молодих і середньовікових соснових деревостанів методами стереофотограмметричного оброблення зображень аерозйомки із БПЛА із наступним застосуванням алгоритму фільтрації максимальних значень має низку недоліків, пов'язаних із неможливістю детектування низьких дерев під пологом лісу та помил- 
ковим виділенням верхівок дерев, що розташовані в межах радіуса фільтрації. Описаними у роботі підходами неможливо здійснити вимірювання висоти для кожного дерева. Однак у лісотаксаційній науці верхня висота деревостану має важливіше значення, ніж середня висота, що зумовлено іiі меншою мінливістю порівняно зі середньою висотою внаслідок меншої залежності від проведення рубань, тому зазначений показник більш вдало використовується для розроблення нормативного забезпечення ходу росту деревостанів, при цьому обидва показники мають сильну тісноту зв'язку (Strochinskiy, 1992). Тому оцінювання верхніх висот $є$ доволі інформативним показником у створені відповідного інформаційного забезпечення.

Таблиця. Розподіл фактичних і прогнозованих висот дерев, отриманих різними способами

\begin{tabular}{|c|c|c|c|c|c|c|c|}
\hline \multirow{3}{*}{ Висота, м } & \multicolumn{7}{|c|}{ Кількість ідентифікованих верхівок, шт. } \\
\hline & \multirow{2}{*}{$\begin{array}{c}\text { дерев } \\
\text { лазерно-оптич- } \\
\text { ним приладом } \\
\text { TruPulse } 360 \mathrm{~B}\end{array}$} & \multicolumn{2}{|c|}{$R=0,5 \mathrm{M}$} & \multicolumn{2}{|c|}{$R=0,75 \mathrm{M}$} & \multicolumn{2}{|c|}{$R=1,0 \mathrm{M}$} \\
\hline & & $D$ & $T$ & $D$ & $T$ & $D$ & $T$ \\
\hline $6(5,5-6,4)$ & 1 & - & 3 & - & - & - & - \\
\hline $7(6,5-7,4)$ & - & - & 2 & - & - & - & - \\
\hline $8(7,5-8,4)$ & 2 & - & 1 & - & - & - & - \\
\hline $9(8,5-9,4)$ & 1 & - & 5 & - & - & - & - \\
\hline $10(9,5-10,4)$ & 1 & - & 6 & - & - & - & - \\
\hline $11(10$ & 4 & 4 & 19 & 3 & 6 & 2 & 2 \\
\hline $12(1$ & 17 & 7 & 9 & 5 & 5 & 4 & 4 \\
\hline 13( & 21 & 20 & 21 & 18 & 18 & 14 & 14 \\
\hline$, 5-14,4)$ & 9 & 9 & 9 & 9 & 9 & 6 & 6 \\
\hline $15(14,5-15,4)$ & 1 & 1 & 1 & 1 & 1 & 1 & 1 \\
\hline Всього & 57 & 41 & 76 & 36 & 39 & 27 & 27 \\
\hline
\end{tabular}

Примітка: D - максимуми, що відповідають реальним стовбурам деревам на пробній площі; T - загальна кількість ідентифікованих максимумів (враховуючи помилкові).

Важливішою для практичного застосування зазначеної методології $\epsilon$ саме точність визначення висоти вже для правильно ідентифікованих стовбурів дерев. Для оцінки похибок зазначених показників, порівняли значення висоти дерев, отримані в польових вимірюваннях та за допомогою аерозйомки за різних значень радіусів фільтрації максимальних значень (див. рис. 2).

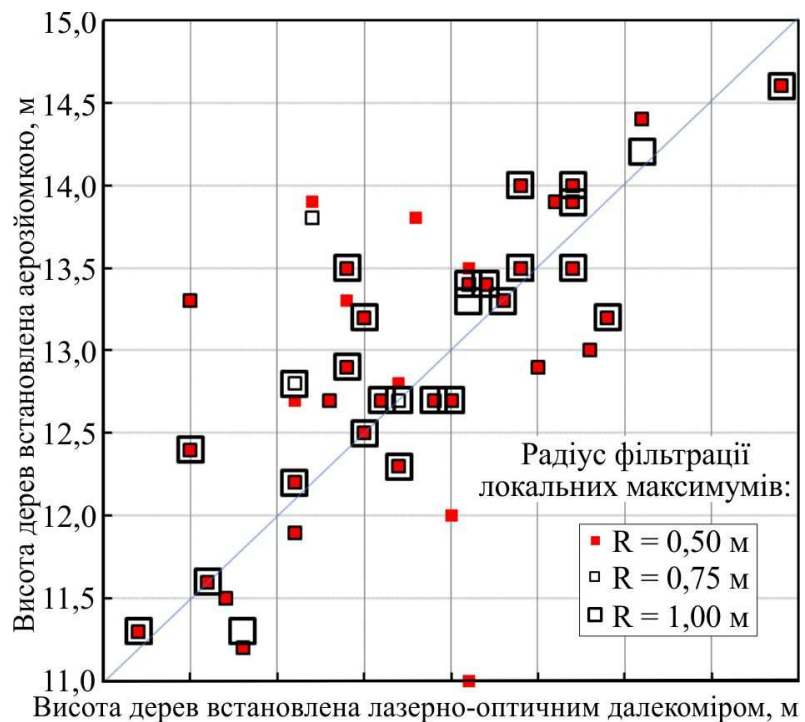

Рис. 2. Співвідношення між значеннями висот дерев, отриманих різними способами

Порівняння фактичних висот дерев 3 оціненими аерозйомкою (рис. 2) вказує на зростання точності визначення висоти дерев зі збільшенням радіуса фільтрації максимальних значень СНМ растра, що спричинено потраплянням щораз вищих дерев до вибірки зі збільшенням радіуса фільтрації. Якщо при $R=0,5$ м стандартне відхилення (SD) прогнозованих значень висоти дерев від фактичних становило 0,73 м (41 дерево), то при $R=0,75-0,62$ м (36 дерев) і $R=1,0-0,44$ м (27 дерев), відповідно зростають значення лінійного коефіцієнта кореляції між ознаками $(r)$ : при $R=0,5$ м він становить 0,67 , при $R=0,75-0,78$ м та при $R=1,0-0,88$ м, які $є$ статистично значущими $(p<0,05)$. Правильне детектування високих дерев із доволі точним визначенням їх висоти у разі застосування фільтра пошуку максимумів $R=1,0$ м робить цілком прийнятним застосування методу для молодих і середньовікових деревостанів сосни звичайної. Однак потрібна подальша експериментальна робота у зазначеному напрямку для розробки алгоритмів перетворення дистанційних даних з БПЛА у інформацію, придатну для вирішення задач лісової науки і виробництва.

Висновки. За результатами проведених досліджень встановлено можливість автоматичної ідентифікації верхівок найвищих дерев сосни звичайної у зімкнутих деревостанах, використовуючи засоби ГІС після стереофотограмметричного оброблення зображень аерозйомки із БПЛА, що досягнуто підходами пошуку максимумів на вихідному растрі моделі висоти крон (СНM) iз застосуванням фільтрів різних радіусів $(0,5,0,75$ та 1,0 м). Застосовуючи фільтр радіусом 1,0 м, виявлено найменшу кількість виділених максимумів, однак усі вони відповідали реальним деревам, а також для них спостерігається найкраща точність у визначені висоти $(S D=0,44$ м). Стандартне відхилення у визначені висоти найвищих дерев за допомогою БПЛА наблизилося до рівнів ручних висотомірів. Особливо актуальними зазначені способи є для важко доступних і радіоактивно забруднених лісів Чорнобильської зони відчуження, де перебування людини тривалий час призводить до отримання нею значної дози зовнішнього іонізуючого випромінювання.

Acknowledgements. The research in the article was carried out within the framework of the joint Japan-Ukraine project SATREPS "The Project for Strengthening of the Environmental Remediation of Radioactively Contaminated Sites". The authors express sincere gratitude to Prof. K. Nanba, Prof. H. Tsukada, Dr. Sh. Uematsu and Mr. H. Kataoka for their assistance in organization of the research.

\section{Перелік використаних джерел}

Abdollahnejad, A., Panagiotidis, D., \& Surový, P. (2018). Estimation and extrapolation of tree parameters using spectral correlation between UAV and Pléiades data. Forest, 9, 85. https://doi.org/10.3390/19020085

Brovkina, O., Cienciala, E., Surový, P., \& Janata, P. (2018). Unmanned aerial vehicles (UAV) for assessment of qualitative classification of Norway spruce in temperate forest stands. Geo-spatial Information Science, $21(1), \quad 12-20$. https://doi.org/10.1080/10095020.2017.1416994

Giannetti, F., Chirici, G., Gobakken, T., Naesset, E., Travaglini, D., \& Puliti, S. (2018). A new approach with DTM-independent metrics for forest growing stock prediction using UAV photogrammetric data. Remote Sensing of Environment, 213, 195-205. https://doi.org/10.1016/j.rse.2018.05.016

Goodbody, T., Coops, N., Marshall, P., Tompalski, P., \& Crawfordb, P. (2017). Unmanned aerial systems for precision forest inventory 
purposes: A review and case study. The Forestry Chronicle, 93(1), 71-81. https://doi.org/10.5558/tfc2017-012

Mohan, M., Silva, C., Klauberg, C., Jat, P., Catts, G., Cardil, A., Hudak, A. T., \& Dia, M. (2017). Individual tree detection from unmanned aerial vehicle (UAV) derived canopy height model in an open canopy mixed conifer forest. Forests, 8, 340. https://doi.org/10.3390/f8090340

Oteroa, V., Kerchoveb, R., Satyanarayanaa, B., Martínez-Espinosa, C., Fisolc, M., Ibrahimc, M., Sulongc, I., Mohd-Lokmanc, H., Lucasd, R., \& Dahdouh-Guebas, F. (2018). Managing mangrove forests from the sky: Forest inventory using field data and Unmanned Aerial Vehicle (UAV) imagery in the Matang Mangrove Forest Reserve, peninsular Malaysia. Forest Ecology and Management, 411, 35-45. https://doi.org/10.1016/i.foreco.2017.12.049

Panagiotidis, D., Abdollahnejad, A., Surový, P., \& Chiteculo, V. (2017). Determining tree height and crown diameter from high-re- solution UAV imagery. International Journal of Remote Sensing, 38(8-10), https://doi.org/10.1080/01431161.2016.1264028

Puliti, S., Ene, L., Gobakken, T., \& Naesset, E. (2017). Use of partialcoverage UAV data in sampling for large scale forest inventories. Remote Sensing of Environment, 194, 115-126. https://doi.org/10.1016/j.rse.2017.03.019

Strochinskiy, A. A. (1992). Methodical and normative-information provision of a system for regulating the forest plantations productivity in Ukraine. Kyiv: UACA. [In Russian].

Wallace, L., Lucieer, A., Malenovský, Z., Turner, D., \& Vopenka, P. (2016). Assessment of forest structure using two UAV techniques: A comparison of airborne laser scanning and structure from motion $\begin{array}{lllll}\text { (SfM) point clouds. Forests, } & 7, & 62 .\end{array}$ https://doi.org/10.3390/f7030062

\section{Д. Н. Голяка 1 Х. Като ${ }^{2}$ В. И. Йощенко ${ }^{3}$, Я. Игараши ${ }^{3}$, Ю. Онда $^{2}$, А. А. Аврамчук ${ }^{1}$ М. А. Голяка 1 , В. В. Гуменюк ${ }^{1}$, А. Н. Лесник ${ }^{1}$}

${ }^{1}$ Национальный университет биоресурсов и природопользования Украины, г. Киев, Украина ${ }^{2}$ Университет Цукуба, г. Цукуба, Япония ${ }^{3}$ Фукусимский университет, г. Фукусима, Япония

\section{ИДЕНТИФИКАЦИЯ И ОЦЕНКА ВЫСОТЫ ДЕРЕВЬЕВ СОСНЫ ОБЫКНОВЕННОЙ В НАСАЖДЕНИЯХ ЧЕРНОБЫЛЬСКОЙ ЗОНЫ ОТЧУЖДЕНИЯ СТЕРЕОФОТОГРАММЕТРИЧЕСКИМ СПОСОБОМ}

Рассмотрены возможности использования аэрофотосъемки с помощью беспилотного летательного аппарата и последующей обработки полученных изображений стереофотограмметрическими подходами для идентификации деревьев сосны обыкновенной и оценки их высоты в сомкнутых древостоях способом сравнения данных, полученных для круговой пробной площади в результате аэрофотосъемки и в полевых условиях лазерно-оптическими дальномерами, которые использовались как контрольные значения. Установлена возможность идентификации верхушек стволов деревьев сосны обыкновенной с помощью алгоритмов поиска максимумов растров в программных продуктах ГИС. Подтверждена невозможность детектирования деревьев нижних элементов яруса путем применения радиусов поиска максимумов малых размеров $(0,5$ м), что вызывает попадание в выборку значительного количества ложных деревьев. Увеличение размеров радиуса (1,0 м) фильтрации выявления максимальных значений растра цифровой модели высот крон исследуемого древостоя позволило с достаточной точностью оценить высоту (стандартное отклонение 0,44 м) 27 деревьев в верхней части лесного полога. Это свидетельствует о перспективности использования перечисленных подходов для установления лесотаксационных параметров насаждений не только с научными целями, но и при проведении лесоустройства и лесоинвентаризации, поскольку верхняя высота древостоя имеет тесные функциональные связи с другими таксационными признакам.

Ключевые слова: беспилотный летательный аппарат; лесная таксация; дерево; аэросъемка; ГИС; растр; модель высоты крон (СНM).

\section{M. Holiaka1, H. Kato', V. I. Yoschenko3, Ya. Igarashi, Yu. Onda', O. O. Avramchuk1, M. A. Holiaka1, V. V. Humenyuk1, O. M. Lesnyk ${ }^{1}$ \\ ${ }^{I}$ National University of Life and Environmental Sciences of Ukraine, Kyiv, Ukraine \\ ${ }^{2}$ University of Tsukuba, Tsukuba, Japan \\ ${ }^{3}$ Fukushima University, Fukushima, Japan}

\section{IDENTIFICATION AND ESTIMATION OF HEIGHTS OF SCOTS PINE TREES IN FOREST STANDS IN THE CHERNOBYL EXCLUSION ZONE USING STEREOPHOTOGRAMMETRY METHOD}

The paper discusses the possibilities of identification of the tops of Scots pine (Pinus sylvestris L.) trees and the subsequent assessment of their heights in forest stands using aerial photographs made from an unmanned aerial vehicle and stereo photogrammetric processing. The research was carried out in a young forest stand composed of the trees of different ages (up to 30 year old) and growing within a circular plot with a radius of $12.6 \mathrm{~m}$. Within the studied area we determined coordinates of all live pine trees and measured their heights using a laser-optical rangefinder. This field data was used for estimation of the inaccuracies of determination of the tree heights using the drone. The study confirmed applicability of the drone survey method for identification of the tops of the highest trees using the GIS filter tools for search local maxima in the output raster images of the canopy height model. Research results have confirmed the impossibility of detecting the stem tops of trees if they do not occupy the dominant position in the forest stands. We used three different search radiuses for detection of local maximum values for identifying the following tree tops: $0.5 \mathrm{~m}, 0.75 \mathrm{~m}$ and $1.0 \mathrm{~m}$. Reduction of the search radius in order to identify the trees in the lower tier resulted in the false detection of a numerous local maxima (branch tops) as the separate trees. The best result was obtained with the largest search radius, since all the found maxima corresponded to the actual individual trees, and their heights were estimated with the smallest deviations from the values measured in field using a laser-optical rangefinder (the standard deviation was $0.44 \mathrm{~m}$ for 27 trees detected in the upper tier), although the number of detected trees was smaller comparing to those obtained with the shorter search radiuses. We have concluded that the above-mentioned remote detection approach has good prospects for application both in scientific researches and in forest inventory considering that the upper height of the forest stands is closely correlated with other forest parameters, especially since stereo photogrammetry methods are rapidly evolving and modified for solution increasingly complex problems.

Keywords: unmanned aerial vehicle; forest inventory; tree; aerial photography; GIS; raster; canopy height model (CHM). 